Borneo Journal of Sciences and Technology, Volume (2), Issue (1), Pages: 27-31

DOI: https://doi.org/10.35370/bjost.2020.2.1-06

e-ISSN: 2672-7439

(C) 2018, UCTS Publisher.

Submitted: $6^{\text {th }}$ May 2019

Accepted: $15^{\text {th }}$ August 2019

Published: $31^{\text {th }}$ January 2020

\title{
Experimental Study on Voided Slab Subjected to Flexural Load
}

\author{
Alicia Yik Yee Min and Ling Jen Hua \\ School of Engineering and Technology, University College of Technology Sarawak, 96000 Sibu, \\ Sarawak, Malaysia
}

\begin{abstract}
Concrete weight constitutes a large portion of load in a reinforced concrete structure. To reduce the load, void formers such as polystyrene can be embedded in the slabs. This study investigates the behaviour of one-way slabs embedded with polystyrene of different shapes (sphere, cylinder and rectangular). A solid slab and three voided slabs were tested under an incremental flexural load using the four point load test setup. The load capacity, crack pattern and ductility of the specimens were to determine the effects of the shapes of polystyrene in slabs. The spherical and cylindrical shape offered a better structural performance than rectangular. For the smooth edges that allows better distribution of the stress, the specimens gave a higher load capacity and ductility than rectangular shapes. Voided slabs with $10.6 \%$ concrete replacement by spherical and cylindrical polystyrene offered a comparable load capacity but lower ductility than the solid slab.
\end{abstract}

Keywords: One-way voided slab, experimental investigation, polystyrene, geometrical properties.

\section{INTRODUCTION}

Reinforced concrete (RC) slab is a building element constructed as the floor and ceiling. It distributes the loads acting on a building in one or two directions to the adjacent beams or directly to the columns [1]. As concrete weight constitutes a large portion of permanent load in a RC structure, it would be economical if the weight of the slab could be reduced. For that, studies were carried out to reduce the weight of concrete slab [2].

There are several voided floor systems, namely Bubbledeck system, Cobiax system, U-boot Beton and Airdeck floor slab. Bubbledeck and Cobiax systems use plastic spheres to replace the concrete in slabs [3, 4]. U-boot Beton uses grip-shaped beams to replace concrete [4]. Airdeck embeds polypropylene materials in slabs [3].

Due to proprietorship, there are limited publications regarding the voided slab systems. Alternatively, polystyrene, in various shapes, can be embedded in the slabs as it can be made into various shapes [5].

This paper studies the behaviour of voided oneway slab incorporating polystyrene of different shapes under incremental flexural load. The aim is to determine a shape which offers the best performance of slab.

\section{MATERIALS AND METHODS}

\section{Specimen}

Four specimens in a size of $1600 \mathrm{~mm}$ (L) X $750 \mathrm{~mm}$ (W) x $200 \mathrm{~mm}(\mathrm{H})$ were prepared. This included a solid slab as the control specimen and three voided slab specimens. The polystyrene embedded in the voided slabs were in the shapes of sphere, cylinder and rectangular.

Steel bars with a specified yield strength of 460 $\mathrm{N} / \mathrm{mm}^{2}$ were provided as the reinforcement bars at the bottom of the slabs. The main and secondary reinforcement bars were T10-150 mm and T10-200 $\mathrm{mm}$, respectively (Figures 1). The concrete cover designed was $20 \mathrm{~mm}$.

The polystyrene with a height of $120 \mathrm{~mm}$ were placed in the slab at a spacing of $45 \mathrm{~mm}$ throughout. It replaced $10.6 \%$ of concrete in the slab. The details of the polystyrene are given in Figure 2 and Table 1.

The polystyrene was tied on the steel reinforcement using galvanized wire. Formworks were fabricated using a series of plywood and hardwood. Ready-mixed concrete of grade 25 and slump $100 \mathrm{~mm}$ to $175 \mathrm{~mm}$ were used for casting. The specimens were cured for 28 days by spraying water on the surface once a day. 


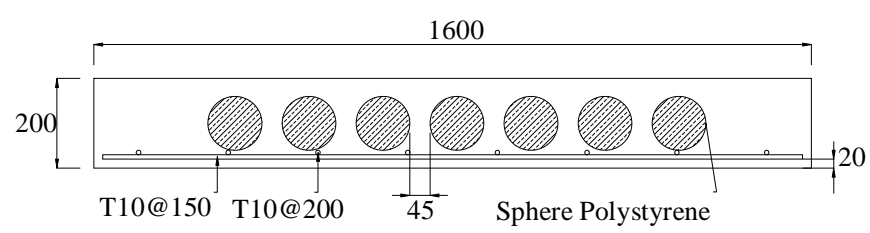

(a) Voided Slab 1 (VS1)

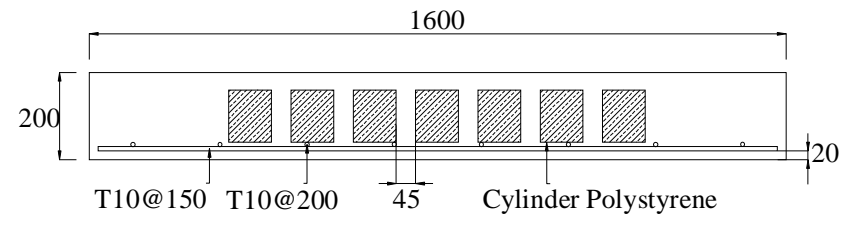

(b) Voided Slab 2 (VS2)

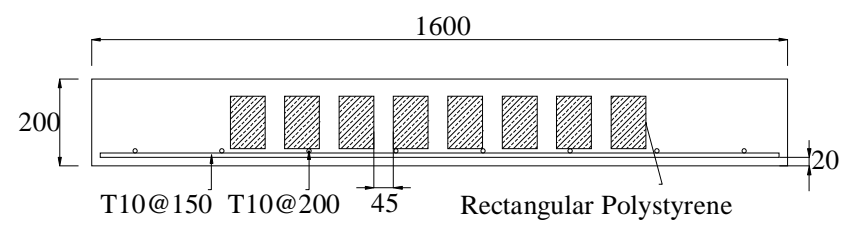

(c) Voided Slab 3 (VS3)

Figure 1: Front View of the Specimen
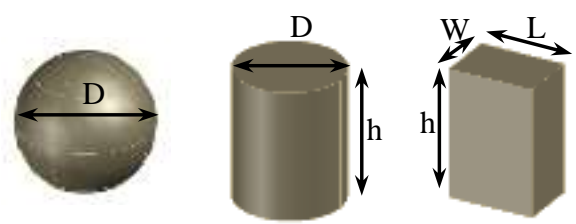

Figure 2: Details of the Geometrical Properties

Table 1: Details of the specimens

\begin{tabular}{ccccccc}
\hline Slab & \multicolumn{5}{c}{ Geometrical Properties } \\
\cline { 2 - 7 } & Shape & $\begin{array}{c}\text { D, } \\
\mathrm{mm}\end{array}$ & $\begin{array}{c}\mathrm{W}, \\
\mathrm{mm}\end{array}$ & $\begin{array}{c}\mathrm{L}, \\
\mathrm{m}\end{array}$ & $\begin{array}{c}\text { h, } \\
\mathrm{mm}\end{array}$ & $\begin{array}{c}\text { Concrete } \\
\text { Reductio } \\
\text { n, \% }\end{array}$ \\
\hline CS & - & - & - & - & 120 & - \\
VS1 & Sphere & 120 & - & - & 120 & 10.6 \\
VS2 & Cylinder & 98 & - & - & 120 & 10.6 \\
VS3 & Rect & - & 55 & 80 & 120 & 10.6 \\
\hline \multicolumn{7}{l}{ Note: D = Diameter, W = Width, L = Length }
\end{tabular}

\section{Experimental Setup}

Four-point load test was carried out on the specimen using a $300 \mathrm{kN}$ hydraulic jacking system (Figure 3). The specimens were supported by a set of pin and roller support with an effective span length of 1500 $\mathrm{mm}$. Two steel plates were placed on the slab with a distance of $1 / 3$ of the effective span length. A steel Ibeam was placed on top of two steel plates to distribute the load acting onto the specimen.

A load cell was placed in between the hydraulic jack and the I-beam to measure the load applied onto the specimen.
Five Linear Variable Differential Transducers (LVDT) were placed under the specimen to measure the deflection (Figure 4).

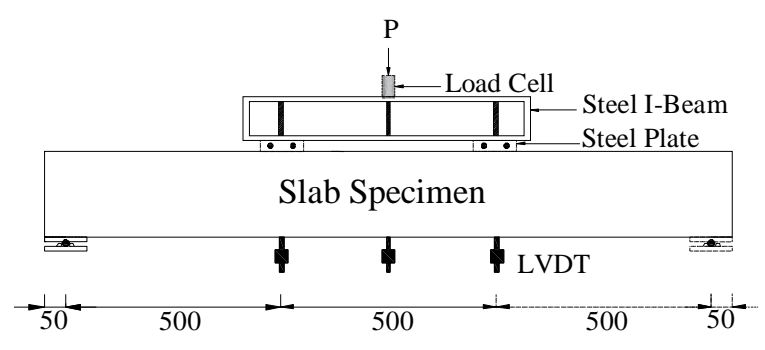

Figure 3: Experimental Setup

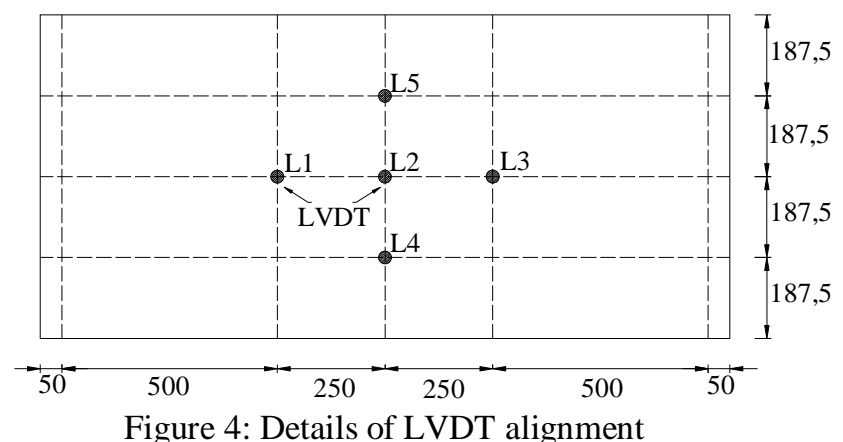

Test Procedure

A preload of $5 \mathrm{kN}$ was applied twice to consolidate the test setup and to cross-check if the instrumentations were in good conditions. The preload was released and the readings were re-initialized to zero after 5 minutes. The specimen was then incrementally loaded at an interval of $0.1 \mathrm{~mm}$ deflection. During testing, the crack patterns on the specimen surface were monitored. The specimen was considered fail when a noticeable drop was observed on three consecutive readings.

\section{RESULTS AND DISCUSSION}

\section{Material Properties}

Concrete cubes (150 mm size) were tested on day 28 to determine the concrete strength of the specimens. The strength ranged between $25 \mathrm{~N} / \mathrm{mm}^{2}$ and $29 \mathrm{~N} / \mathrm{mm}^{2}$ (Table 2) which is higher than the desired strength of $25 \mathrm{~N} / \mathrm{mm}^{2}$.

Three steel bar samples were tested to determine the tensile strength of the bars. The average tensile strength was $562 \mathrm{~N} / \mathrm{mm}^{2}$ which is higher than the specified yield strength of $460 \mathrm{~N} / \mathrm{mm}^{2}$ (Table 3).

The quality of the materials used in the study is considered acceptable. 
Experimental Study on Voided Slab Subjected to Flexural Load

Table 2: Concrete Strength

\begin{tabular}{ccccc}
\hline \multirow{2}{*}{ Specimen } & $\begin{array}{c}\text { Sample, } \\
\mathrm{mm}\end{array}$ & \multicolumn{2}{c}{$f_{\text {cu }}\left(\mathrm{N} / \mathrm{mm}^{2}\right)$} & $f_{\text {cu,avg }}$ \\
\cline { 3 - 4 } & & $\mathrm{C} 1$ & $\mathrm{C} 2$ & $\left.\mathrm{~N} / \mathrm{mm}^{2}\right)$ \\
\hline CS & & 25.1 & 25.3 & 25.2 \\
VS1 & \multirow{2}{*}{ 150 Cube } & 26.0 & 29.8 & 27.9 \\
VS2 & & 29.2 & 30.0 & 29.6 \\
VS3 & & 29.2 & 30.0 & 29.6 \\
\hline
\end{tabular}

Table 3: Tensile Strength

\begin{tabular}{ccccc}
\hline $\begin{array}{c}\text { Diameter, } \\
\text { mm }\end{array}$ & \multicolumn{3}{c}{ Yield Strength, $f_{y k}\left(\mathrm{~N} / \mathrm{mm}^{2}\right)$} & \begin{tabular}{c}
$f_{y k \text { avg }}$ \\
\cline { 2 - 4 }$\left(\mathrm{N} / \mathrm{mm}^{2}\right)$
\end{tabular} \\
\hline $\mathrm{T} 10$ & 498 & 587 & 602 & 562.3 \\
\hline
\end{tabular}

\section{Load-displacement Relationship}

Figure 5 compares the load-displacement responses of the solid and voided slabs. Table 4 presents the test results in terms of the first crack load, yield load and ultimate load of the specimens.

In general, the specimens offered a high degree of stiffness at the early stage of loading, as represented by the gradient of the load-displacement curve. The deflection developed proportionally to the load applied. The first crack, which occurred around $54 \mathrm{kN}$ load, affected the stiffness of the specimens slightly, where the deflection developed at a slightly faster rate.

The specimens yielded around $150 \mathrm{kN}$. The stiffness decreased drastically and large deflections developed with respect to small increments of load.

The specimens peaked around $180 \mathrm{kN}$ load. It had reached the ultimate state and was considered failed.

In terms of the structural performance, voided slabs were inferior to the solid slab. The stiffness, first crack load, yield load and ultimate load were generally lower than the solid slab. The removal of concrete in the slab affected the distribution of stress in it, and subsequently, influence the performance of slab.

Among the voided slabs, specimen VS2 (cylinder) gave the highest ultimate and yield loads of $183.83 \mathrm{kN}$ and $162.10 \mathrm{kN}$ respectively. This was followed by specimen VS1 (sphere) offering $175.85 \mathrm{kN}$ load capacity.

Specimen VS3 (rectangular) offered the lowest first crack load, yield load and ultimate load. It failed abruptly after reaching the ultimate state. High stress concentrated at the sharp corners of the rectangular shape, and this led to early failure of the specimen.

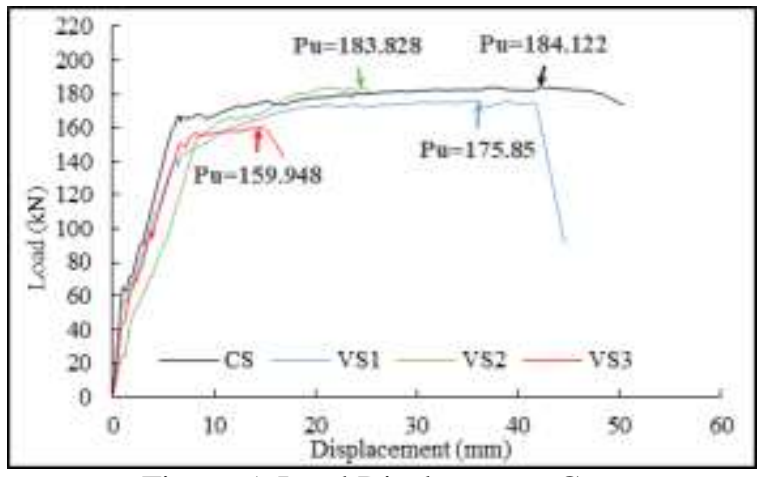

Figure 5: Load Displacement Curve

Table 4: First Crack Load, Yield Load, Ultimate Load

\begin{tabular}{llll}
\hline Slab & $\mathrm{P}_{\mathrm{cr}}, \mathrm{kN}$ & $\mathrm{P}_{\mathrm{y}}, \mathrm{kN}$ & $\mathrm{P}_{\mathrm{u}}, \mathrm{kN}$ \\
\hline CS & 62.97 & 163.94 & 184.12 \\
VS1 & 54.12 & 145.18 & 175.85 \\
VS2 & 54.05 & 162.10 & 183.83 \\
VS3 & 44.28 & 150.89 & 159.95 \\
\hline
\end{tabular}

Note: $\mathrm{P}_{\mathrm{cr}}=$ First Crack; $\mathrm{P}_{\mathrm{y}}=$ Yield Load; $\mathrm{P}_{\mathrm{u}}=$ Ultimate Load

\section{Crack Pattern}

Figure 6 presents the crack patterns of the specimens. Specimens CS, VS1 and VS2 demonstrated the flexural failure. Several flexural cracks were noticed along the mid span.

The flexural crack first initiated at the mid span from the soffit. It widened and propagated vertically upward as the load increased. Then, a new flexural crack developed at an offset distance about equivalent to the depth of the slab closer towards to support. As the load increased further, more flexural cracks until the ultimate state of the slab was reach.

In addition to the flexural cracks, specimen VS3 showed an inclined shear crack. It developed after several flexural cracks. It propagated from a support toward the nearest point load induced by the hydraulic jack. Reaching the ultimate state, the shear crack developed rapidly and affected the ductility of the specimen. 

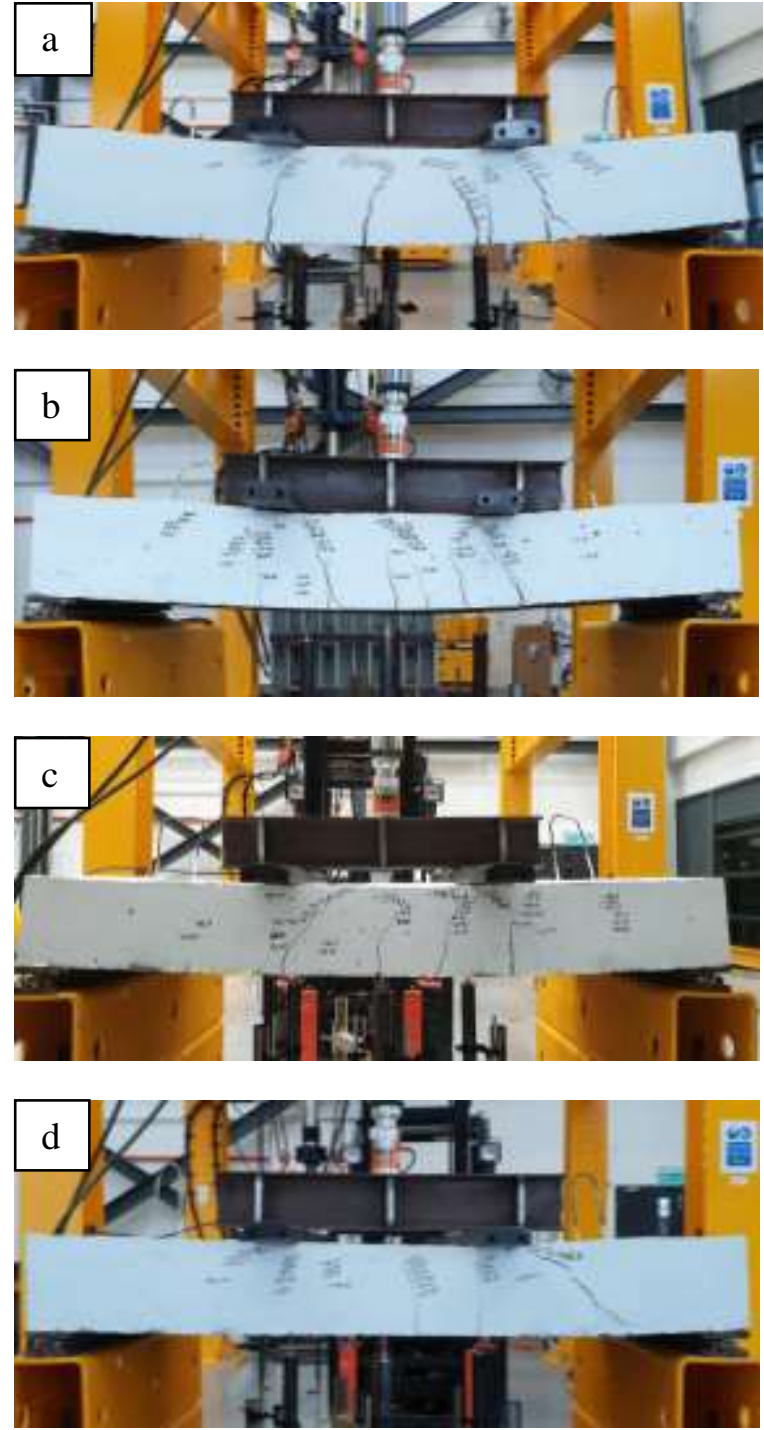

Figure 6: Crack Pattern (a.CS b.VS1 c.VS2 d.VS3)

\section{Effects of Geometrical Properties}

Table 5 evaluates the performance of the specimens in terms of the ductility and load ratios. The specimen with higher values of ductility and load ratios gives a better structural performance.
Table 5: Performance of slabs

\begin{tabular}{ccccc}
\hline Slab & $\delta_{\mathrm{y}}, \mathrm{mm}$ & $\begin{array}{c}\delta_{\mathrm{u}}, \\
\mathrm{mm}\end{array}$ & $\begin{array}{c}\text { Ductility } \\
\text { ratio, } \\
\delta_{\mathrm{u}} / \delta_{\mathrm{y}}\end{array}$ & $\begin{array}{c}\text { Load ratio, } \\
\mathrm{P}_{u, i} / \mathrm{P}_{u, c}\end{array}$ \\
\hline $\mathrm{CS}$ & 6.60 & 42.16 & 6.39 & 1.00 \\
$\mathrm{VS} 1$ & 7.30 & 36.11 & 4.95 & 0.97 \\
$\mathrm{VS} 2$ & 10.0 & 24.47 & 2.45 & 0.99 \\
$\mathrm{VS} 3$ & 6.72 & 14.44 & 2.15 & 0.87 \\
\hline Note: $\delta_{\mathrm{y}}=$ Yield & Displacement; $\delta_{\mathrm{u}}=$ Ultimate \\
Displacement; $\mathrm{P}_{u, i}=$ Ultimate load of the test specimen; \\
$\mathrm{P}_{u, c}=$ Ultimate load of the control specimen
\end{tabular}

In general, voided slabs offered a lower strength and ductility than the solid slab. Replacing $10.6 \%$ concrete in slab with void formers affected less than $3 \%$ of the capacity of the slab. In terms of the strength per unit volume of concrete, the voided slabs were more efficient.

The shape of the void former in slab affected the performance of slab. Sphere and cylinder offered a higher strength and ductility than rectangular.

The sharp corners of the rectangular polystyrene led to concentration of high stress in the slab, and subsequently led to earlier failure of the slab. For the reason, polystyrene in curvilinear shape and with smooth edges is preferred. It (a) allows stress to be more evenly distributed surrounding the void formers, (b) deters propagation of the shear crack, and (c) prevent the slab to fail prematurely in brittle manner.

\section{CONCLUSION}

The structural behaviour of the one way voided slab was investigated based on the load capacity, crack pattern and ductility.

It is concluded that:

1. The voided slabs with polystyrene in spherical and cylindrical shapes were more efficient in terms of the strength per unit concrete volume. Replacement of $10.6 \%$ concrete in the slab led to less than $3 \%$ reduction in strength. Thus, it is possible to develop voided slab by using polystyrene.

2. The voided slabs demonstrated a similar loaddisplacement response and crack pattern as the solid slab. The stiffness, strength and ductility were generally lower.

3. For the smooth edges that evenly distribute stress in the slab, voided slab having spherical and cylindrical polystyrene outperformed the rectangular shape in terms of the strength and ductility. Thus, the spherical and cylindrical shapes are preferred. 


\section{ACKNOWLEDGMENT}

This work was supported by the research grant (UCTS/RESEARCH/2/2018/02) of University College of Technology Sarawak.

\section{REFERENCES}

[1] Mosley, W. H., and Bungey, J. H. 1982. Reinforced Concrete Design. 2nd Edn., The Micmillan Press Ltd, Basingstoke, London.

[2] Alfeehan, A. A., Abdulkareem, H. I. and Mutashar, S. H. 2017. Flexural Behavior of Sustainable Reactive Powder Concrete Bubbled Slab Flooring Elements. Challenge Journal of Structural Mechanics, 3(2), 81.

[3] Dwivedi, A. K., Joshi, H. J., Raj, R., Mishra, P. P., Kadhane, M. and Mobahey, B. 2016. Voided Slab Design: Review Paper. $3^{\text {rd }}$ International Conference on Multidisciplinary Research \& Practice. IJRSI.

[4] Churakov, A. 2014. Biaxial Hollow Slab with Innovative Types of Voids. Construction of Unique Buildings and Structures, 70-88.

[5] Izzat, A. F., Farhan, J. A. and Allawi, N. M. 2014. Behaviour and Strength of One Way Reinforced Concrete Slabs with Cavities. International Conference for Engineering Science. Baghdad University Of Mustansiriyah. 